REVIEW ARTICLE

\title{
A Review of the Causes of Japanese Students' Educational Demotivation Through PROSPER Model
}

Steven Samie

Researcher

\begin{abstract}
:
The purpose of the present project was to review the research studies which have been carried on educational demotivation among Japanese students in general. This project reviews the possible causes of educational demotivation among Japanese students which could lead to their underachievement at times and seeks to contribute to the body of wellbeing research studies which have been conducted on various levels of education in Japan. Based on research studies, many factors have been identified, such as psychological, social, and cultural aspects which have huge impacts on learners' motivation. Although many studies have focused namely on motivation, demotivation has not been given its due attention from scholars.
\end{abstract}

Keywords: Educational demotivation, Japanese students, motivation, PROSPER model

\section{Introduction}

Many definitions have been offered for the term wellbeing, but the one which has been offered by Noble and McGrath (2012) and has been used in many research papers and can be described as student wellbeing is a sustainable state of a positive mood and attitude, resilience and self-satisfaction, and relationships and experiences at school. The increasing focus on student wellbeing aimed at the enhancement of students' social, emotional and academic competence and to diminish youth depression, suicide, self-harm, antisocial behavior (including bullying and violence) and substance abuse (Noble \& McGrath, 2012).

According to reports presented by Organization for Economic Co-operative and Development (2015), many Japanese primary school students struggle with life satisfaction and wellbeing. These students outperform their international peers in many subjects; however, it has been quite a mystery why they tend to be dissatisfied when it comes to mental wellbeing (Ray \& Margaret, 2003). Adopting the Positivity, Relationships, Outcomes, Strengths, Purpose, Engagement, and Resilience (PROSPER) Model developed by Noble and McGrath (2015), this project will review the possible causes of distress and frustration among Japanese students which could lead to their underachievement at times. This project seeks to contribute to the body of wellbeing research studies that have been conducted on various levels of education in Japan.

Various scholars in the field have carried out studies on different dimensions of students' wellbeing in Japan to strengthen the literature in this line of research. Asakawa (2010) conducted 
a research study to show how autotelic people who live in a non-Western culture feel, behave and think in their daily lives. The findings of his study revealed that, on average, Japanese college students experienced an optimal state of mind in which they are cognitively effective, deeply engaged, and highly motivated, as well as having a high level of pleasure, more than a few times a year, but less than once a month. Japanese college students, or those who experienced an optimal state of mind more often in their everyday lives, were also more likely than their less autotelic counterparts to exhibit higher self-esteem and lower anxiety, more frequently used active coping strategies and less frequently used passive coping strategies.

Liu et al. (2009) explored the psychological wellbeing, depression, and anxiety in Japanese university students. The results of their study indicated that all six dimensionsautonomy (AU), environment mastery (EM), personal growth (PG), positive relationships with others (PR), purpose in life (PL), and self- acceptance (SA) - as assessed by the Hospital Anxiety and Depression Scale - the Scales of Psychological Wellbeing Inventory (SPWB) were moderately negative with depression and anxiety (HADS).

Yamawaki et al. (2011) examined self-esteem and life satisfaction in Japanese young adults as mediators between parental bonding and psychological wellbeing in another study. The findings showed that the relationship between parental bonding (parental care and parental overprotection) and general mental health was completely mediated by self-esteem.

Also, Irie and Kengo (2019) investigated the effects of mindfulness and living conditions on the wellbeing of first-year university students in Japan. Their findings demonstrated that an intervention to promote dispositional mindfulness could be effective in protecting the wellbeing of first-year university students, especially in the case of those who had left their homes and were living alone.

Ye and Ho (2019) conducted a study aiming to investigate what kind of causal relationship would exist among the young generations' privacy concerns, protection behaviors and subjective wellbeing in Japan. The effects of demographic factors (age, gender) and access to the Internet through computers and smartphones were taken into account. Their study revealed some interesting results as follows: (a) Students' privacy concerns had positive direct effects on their protection behaviors, along with their time spent accessing the Internet through computers; and (b) their protection behaviors, as well as their time spent accessing the Internet through computers, had negative direct effects on their subjective wellbeing.

Nakano (1990) studied the effects of Type A behavior and hardiness on depression and physical symptoms in the face of hassles. in the study sample consisted of 107 Japanese female college students. The results indicated that Type A females had less depression under low hassles. There were no hardiness main effects or interactions. Neither Type A behavior nor hardiness moderated the adverse effect of hassles for Japanese women.

By investigating the causes, the article aims to find out some practices that would support some school administrators and principals in Fukuoka to initiate some interventions. Working out the causes along with offering some solutions could significantly boost the wellbeing of Japanese primary and secondary students. 
Such studies have been beneficial and fruitful in some ways; however, there are some gaps which need to be filled by some studies. As stated by educators, there are growing concerns in Japan about a loss in moral standards and declining student motivation, coinciding with a perceived decline in the country's edge in innovation (Schleicher, 2014). Therefore, some investigations on the psychological aspects of students' lives could reveal some facts and solutions which could decrease tension and stress among Japanese primary school students, leading them to go up through educational ranks without suffering any feelings of frustration.

\subsection{PROSPER Model of Wellbeing}

Positive education seeks to teach wellbeing skills as well as academic achievement skills (Seligman, 2011). Positive education is defined by Green et al. (2011) as the incorporation of wellbeing science into an educational environment aimed at improving the resilience and wellbeing of students, staff and the entire school community. Promoting thriving or good mental wellbeing within the school community is the key objective of positive education (Norrish et al., 2013). In supporting the wellbeing of children and teenagers, schools play a crucial role (Dulagil et al., 2016). Study results suggest that student wellbeing and mental health effects are correlated with the school environment. Schools appear to overemphasize academic success and concentrate on finding the shortcomings of students and remediating them. Positive psychology, however, focuses on the individual's particular positive qualities and maximizes his or her ability (Terjesen et al., 2004).

In keeping with the principles of positive psychology, which is the science of the conditions and processes leading to the maximum thriving of people, groups and organizations, the PROSPER framework was developed as an investigative device for the application of positive education (Noble \& McGrath, 2015). As Noble and McGrath (2015) put it, positive education is a recently established field of study emphasizing the implementation of Positive Psychology investigations in academic environments. They stated that the term 'PROSPER' is an acronym stressing the seven key components that positivity, relationships, outcomes, strengths, purpose, engagement, and resilience are contributory factors to wellbeing. These elements are further described as follows:

Positivity: Positivity can be defined simply as the positive state of being (Noble \& McGrath, 2015). Positivity means experiencing positive emotions at school by students, such as feeling healthy, belonging, interested, happy, cheerful, and comfortable (Noble \& McGrath, 2016). In addition, gratitude and affection are included in the capacity for understanding and the ability to engage in optimistic thinking as positive thoughts.

Relation: An emphasis on relationships in school ensures that school staff take strategic action to develop meaningful relationships purposefully, such as peer relationships, student relationships with teachers, staff relationships, and relationships between parents and schools (Noble \& McGrath, 2015). It focuses on building positive and meaningful relationships in this area to teach the prosocial values and social skills that require teaching (Noble \& McGrath, 2016).

Outcomes: Outcomes include advances in goals, a sense of being able to do schoolwork, the recognition that accomplishment depends on hard work and commitment, dedication and a 
growing mind, knowledge of achieving such mastery and achievement (Noble \& McGrath, 2015). When the student achieves a result, a fundamental psychological desire for wellbeing will contribute significantly to their sense of mastery, competence and achievement (Bas \& Firat, 2017).

Strengths: A 'Strength' has been described as a way of behaving, thinking or feeling whereby an individual has a natural ability to do something, enjoys doing it, and is enabled to work optimally while pursuing valued results (Govindji \& Linley, 2007). Awareness of selfcharacteristics, skills, and comprehension of how to implement them in various ways are included in strengths (Noble \& McGrath, 2016).

Purpose: When they perceive that their aims are worthwhile, students have a sense of 'purpose'(Govindji \& Linley, 2007). In the sense of education, the goal is to believe what the students have learned as important and to equate their feelings with greater or broader application than just to themselves. In addition, services to members of the school community, members of the wider society, and members' needs are also included (Bas \& Firat, 2017).

Engagement: In education, engagement is a vital concept because it is a strong indicator of academic performance (Noble \& McGrath, 2016). This aspect relates to students' psychological relationships with learning activities and with school (e.g., enjoying learning, and staying connected, interested, and engaged in learning activities and in school life) (Noble \& McGrath, 2016).

Resilience: This involves not only having the ability to revive after being down, making errors, being in trouble, and being prepared to meet challenging circumstances; but also, supportive and logical abilities to think, adaptive distancing abilities, using humor, constructive abilities to think, and finding support when needed (Noble \& McGrath, 2016).

\subsection{Educational Demotivation}

Due to its crucial function, the concept of motivation has been extensively investigated over the past 30 years in the field of second language learning (e.g., Dörnyei, 1994, 1996, 1998, 2001, 2002, 2003, 2009, 2010; Dörnyei \& Ottó, 1998; Dörnyei \& Ushioda, 2011; Gardner, 1985; Masgoret \& Gardner, 2003; Noels et al., 1999; Oxford \& Shearin, 1994;). In spite of many research studies, a significant dimension of motivation, namely demotivation has not attracted the required attention from scholars (Dörnyei, 2003). Dörnyei (2005) believes that "while both positive and negative factors have an effect on ongoing student behaviors, previous research on motivation has generally ignored negative motivations and conceptualized motivation as a kind of inducement (p.89). Investigators consider demotivation as "another side of motivation" (e.g., Dörnyei \& Ushioda, 2011; Falout, et al., 2009; Falout \& Maruyama, 2004; Kikuchi, 2009; Sakai \& Kikuchi, 2009). They maintain that learners' motivation is exposed to many adverse effects throughout the process of second language learning and acquisition. Dörnyei and Ushioda (2011) contend that these harmful effects may be due to "particular learning-related events or experiences, such as performance anxiety, public humiliation, heavy work demands or poor test results" and "factors in the social learning environment, like the personality and the attitude of the teacher or classroom counter-cultures and peer pressures" (p.148). Demotivation has detrimental effects on language learning processes and outcomes as Falout et al. (2009), state that 
demotivation will adversely affect the attitudes and behaviors of the learner, weaken the dynamics of the classroom community and the motivation of the teacher and will result in longterm and widespread negative learning outcomes (p. 403).

Demotivating factors are called student motivation. No generally accepted concept of demotivation exists. Demotivation may, however, be characterized as the negative effects of different factors that have a negative impact on motivation. This refers to particular external factors that diminish or reduce the motivational basis of a behavioral goal or ongoing action (Dörnyei, 2005, p.90).

\subsection{Academic Motivational Factors}

The word motivation is derived from the Latin verb mover, which means to move, according to Beck (2004). Our gestures or acts are then concerned with motivation and what influences them (p. 3). It is a broad psychological term that we frequently use to understand why individuals participate in specific acts at specific times (Beck, 2004). Schunk (2008), Pintrich (2003), and Meece (2008) describe motivation as "the process of instigating and sustaining goaldirected activity" (p. 4). Motivation is described by Thorkildsen (2002) as "an internal force that activates, guides and maintains conduct over time" (p. ix). The term is used by most psychologists dealing with learning and education motivation to identify those mechanisms that can (a) stimulate and instigate behavior, (b) provide direction or intent for behavior, (c) continue to allow behavior to persist, and (d) contribute to a particular behavior being chosen or preferred (Wlodkowski, 1985, p. 2).

Motivation is viewed by Galbraith (1990) as a term that allows us to understand human behavior and success and as an unpredictable construct that cannot be evaluated or tested directly by the physical or natural sciences. According to him, the word motivation is used by most psychologists to describe mechanisms that can energize human actions and provide guidance or meaning for specific behavior. In other words, we deal with motivational mechanisms that are triggered and maintained by human energy when what we concentrate on or pay attention to deals with the directional component of human motivation when we consider human actions in a learning environment, such as attention, concentration, commitment, perseverance, and initiative. Forsyth and McMillan (1991) define motivation as "purposeful participation in classroom assignments and studies, to master concepts or skills" (p. 39) and motivated students as those who "take learning seriously and strive to get full benefits rather than only having the minimum amount of work needed (p. 40).

Motivation is the most commonly utilized terminology concerning the success or failure of any complex activity (Brown, 2000). The definition which is usually put forth for it is "motivation is the gist of the motives that force the choice of a particular demeanor or target in a positive way" (Brophy, 1983; Dörnyei, 2001; Jarvis, 2005). Academic motivation has to do with motivation particularly related to academic performance and success (Schunk, 2008). It is regarded as a student's proclivity "to find academic activities meaningful and worthwhile and to try to derive the intended academic benefits from them" (Brophy, 1998, pp. 205-206). Deci and Ryan (1985, 2000) suggested that academic motivation encourages students to engage in learning tasks more effectively and pursue their academic goal. On the significance of academic 
motivation, a barrage of studies claimed that there is a significant relationship between students' motivation and their academic functioning (Busato et al., 2000; Pintrich, 2003; Rotgans \& Schmidt, 2012; Sogunro, 2014). Based on research studies, many factors have been identified, such as psychological, social, and cultural aspects which have huge impacts on learners' motivation. Such components are offered by various cognitive and behavioral theories of motivation and encapsulate, but are not restricted to, individuals' beliefs and styles of information processing (Bandura, 1986), the expectation of success (Vroom, 1964), learners' goals (Atkinson, 1974; Dweck, 1986), self-acceptance and believing in one's own ability (Covington, 1992; Covington et al., 1994), cultural values and meaning systems (Maehr \& Nicholls, 1980), and external resources like teachers and instructors (MacIntyre et al., 1998). Learners' functioning in academic milieus can be investigated by incorporating grade point average (GPA) as the major index of learners' academic accomplishments (Steinmayr \& Spinath, 2009). Based on the rich literature, the fairest method to assess academic success, grades and GPAs have been found to be the most frequently utilized scales of academic output (York et al., 2015). To date, many theories regarding motivation have investigated the impacts of numerous components such as learning environment or individual characteristics on motivation (Ryan \& Deci, 2000).

Several studies have looked into the effect of wellbeing and motivation on academic success, with similarly varied findings. For example, Novello et al. (1992) suggested a potential connection between health and performance in which wellbeing appeared to play a significant role, and Berger et al (2011) showed, through a multilevel study, a relationship between socioemotional wellbeing, motivation, self-esteem, social integration, positive perception of a school's ambience, and performance. Gutman and Vorhaus (2012) discovered important associations between four dimensions of wellbeing (emotional, behavioral, social, and school), motivation and performance in a longitudinal study. El Ansari and Stock (2010), on the other hand, discovered a reciprocal relationship between health, educational performance, and wellbeing, the latter operationalized in terms of motivation and satisfaction with the educational experience.

\section{Methods}

The initial review was conducted on Scopus, Google Scholar and Web of Science databases. Searching focused on the English language with the combination of keywords as follows: "Educational demotivation, Japanese students, Motivation, PROSPER Model" to identify the relevant studies from 1988 to 2021. The criteria to show that which studies have been included for further analysis are summarized in the following part. The process of selection is also showed in a flowchart.

The search yielded a wide collection of documents in which only the abstracts and references for valid eligibility were initially screened. The studies that are eligible are:

1) They were published in peer-reviewed journals in English.

2) Participants were Japanese primary students.

3) Participants were assessed to evaluate Educational Demotivation through PROSPER Model. 


\section{Results}

A total of 94 publications were yielded by the initial search criteria (Fig. 1). After a review of abstracts, titles, and references, 10 potentially relevant articles were identified. Based on fulltext, 7 articles met the full inclusion criteria. Related titles and abstracts were reviewed to evaluate the educational demotivation through PROSPER model. However, seven of the studies supported that demotivation plays an important rule for Japanese students.

Figure 1

\section{Flow chart of Included Studies}

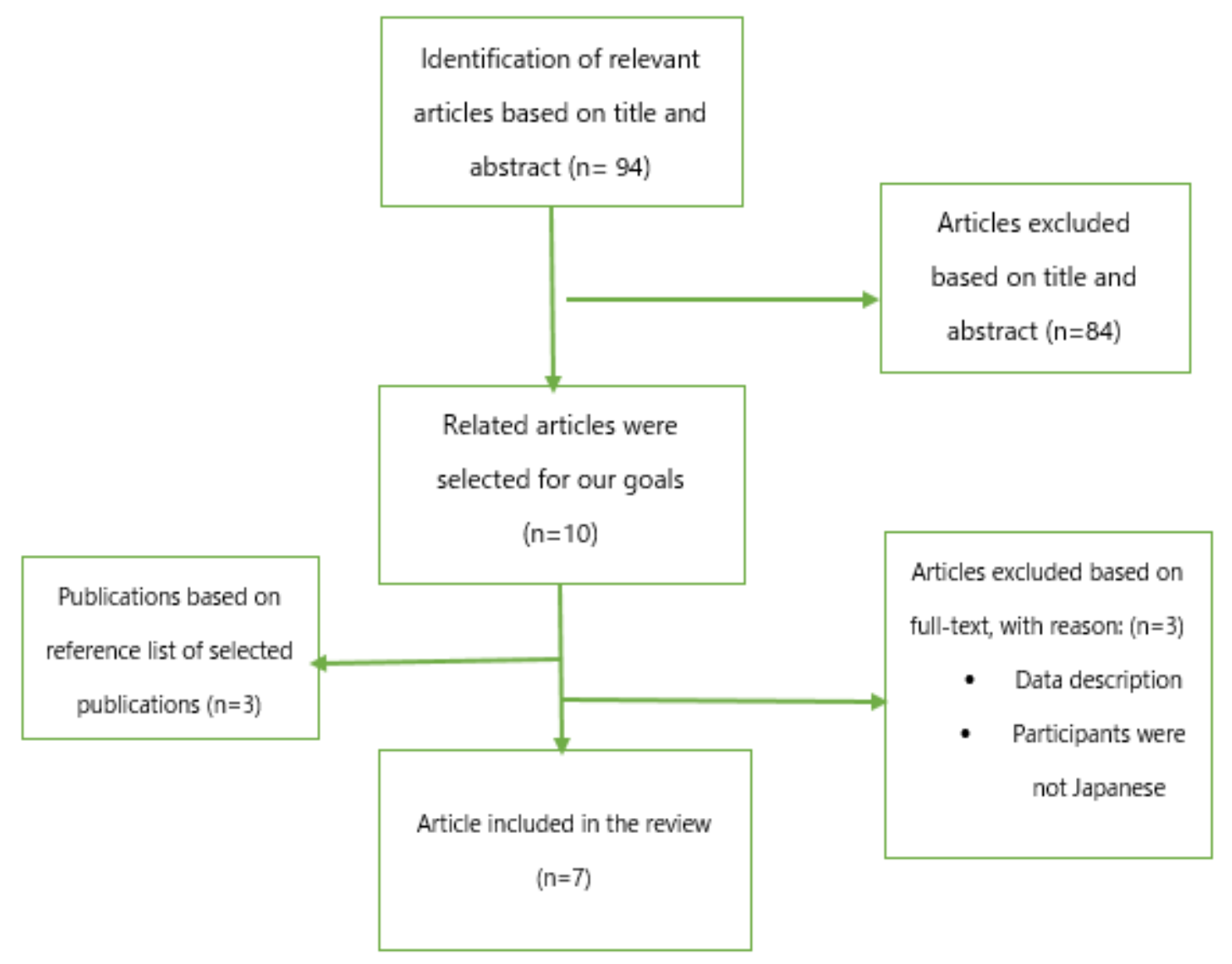

The seven identified articles examined Japanese students' educational demotivation. There exists a common belief among Japanese people that the majority of university students do not have sufficient academic motivation (Manalo et al., 2006). They study very studiously to get admittance into university, but as soon as they enter university, most of them hardly study seriously from an academic perspective (Manalo et al., 2006). They noted that through PROSPER model, the motivation of the students can be increased. Ushiogi (1988) argued that motivation among Japanese students is poor because university education is now commonplace: education no longer guarantees incentives like money, unlike the olden days. In this situation using PROSPER model can be applied to enhance motivation. He noted that education is no longer a passport to escape poverty for most Japanese citizens, as most of them come from families who do not suffer from or even encounter poverty. This view is consistent with the comments made by the General Manager of the Japan Youth Research Institute that Japanese students do not view 
research efforts as necessarily leading to a happier life. In some instances, this issue has been described as "student apathy," and Shimoyama's (1992) comprehensive review of research articles on this topic brings its identification, examination, and apparent increase into the spotlight throughout the last forty years (Manalo et al., 2006).

As Shimoyama (1992) stated, for instance, the good economic situations in Japan throughout the late 1950s ended in greater proportions of people registering for tertiary studies in the 1960s (Manalo et al., 2006). The initial signals for worry, regarding unexpected problems in students' performance, may have appeared in 1964 when, for the first time, a huge number of learners at national universities were not successful in passing their courses. In this way, the motivation of the student should be increased (Manalo et al., 2006).

Tetsushima (1993) discovered that Japanese university EFL teachers are motivated by intrinsic needs and desires such as autonomy, self-growth, and seeing students' progress in English classes on a regular basis. The findings indicate that inner motivational psychological factors can be a strong source of motivation. He noted that teachers can increase the motivation of students through PROSPER model.

Kikuchi (2009) conducted a qualitative study interviewing some Japanese high school students along with a questionnaire to examine what factors were demotivating them in EFL classrooms. The participants of the study comprised five college students participating in two private universities and one public university, who presented their opinions on the issue of demotivation in the interviews. Also, forty-two students at a public university filled out a questionnaire containing solely open-ended response questions. The qualitative analysis revealed five major factors to be the causes of demotion among the students namely (1) individual teacher behavior in the classroom; (2) the method of grammar-translation used in teaching; (3) assessments and university entrance exams; (4) the memorization aspect of vocabulary learning; and (5) problems relevant to textbook/reference books. The finding showed that all the students had poor motivation that should be increased and one of the proposed models to achieve this goal is PROSPER model. In a very similar vein, Arai (2004) and Hasegawa (2004) employed some questionnaires in their studies to examine the subjects' experiences of demotivation in their journey of studying English. In keeping with the projects carried out in contexts other than Japan, the findings of these two research projects too revealed that teachers' behavior frequently frustrates the learners' attempts to learn English, so this causes demotivation between students.

Table 1

Article Included in the Review

\begin{tabular}{|c|c|c|c|}
\hline & Author(s) & Year of publication & Main finding(s) \\
\hline $\mathbf{1}$ & Ushiogi & 1988 & $\begin{array}{c}\text { Motivation among Japanese students } \\
\text { is poor }\end{array}$ \\
\hline $\mathbf{2}$ & Shimoyama & 1992 & $\begin{array}{c}\text { Poor motivation among Japanese } \\
\text { students }\end{array}$ \\
\hline
\end{tabular}




\begin{tabular}{|c|c|c|c|}
\hline 3 & Tetsushima & 1993 & $\begin{array}{c}\text { Motivation among students is poor. } \\
\text { Inner motivational psychological } \\
\text { factors can be a strong source of } \\
\text { motivation. }\end{array}$ \\
\hline $\mathbf{4}$ & Manalo et al. & 2006 & $\begin{array}{c}\text { Poor motivation among Japanese } \\
\text { students }\end{array}$ \\
\hline $\mathbf{5}$ & Aria & 2004 & $\begin{array}{c}\text { Poor motivation among Japanese } \\
\text { students }\end{array}$ \\
\hline $\mathbf{6}$ & Hasegawa & 2004 & $\begin{array}{c}\text { Poor motivation among Japanese } \\
\text { students }\end{array}$ \\
\hline $\mathbf{7}$ & Kikuchi & 2009 & $\begin{array}{c}\text { Poor motivation among Japanese } \\
\text { students }\end{array}$ \\
\hline
\end{tabular}

\section{Discussion}

These research investigations have all been fruitful for the education context of Japan given the fact that they all have addressed the causes in-depth and offered many solutions for this serious crisis in the Japanese educational system.

Based on the data, among other things, the attempts to increase student positivity are in the form of giving students more freedom to think and give opinions, building their motivation. Principals and teachers should use the lecture and advice approach, based on their beliefs, to promote positive thinking among students in daily life (Kikuchi, 2009).

Physically, before all of them go home from school, teachers and principals should attempt to keep students under control. Schools have sought, psychically, to construct a fun learning environment. In the classroom, a fun environment can make individuals feel comfortable. Via seminars, instruction, and tangible measures in the form of behavioral examples, schools taught students social skills and prosocial values. Specific preparation to improve the social skills of students was not implemented (Manalo et al., 2006).

Students were motivated to develop their accomplishments by being taught how to solve everyday problems through the learning process of problem-solving (Shimoyama, 1992). Prior to the competition, the talents and interests of the students are built through extracurricular activities and coaching activities. Teachers should teach them how to think more deeply, especially in mathematics and natural science subjects, by using cause-and-effect questions. The students are also taught outside the classroom how to think deeply (Hasegawa, 2004).

Teachers should provide students with opportunities to engage in group work events coordinated by the teachers themselves. Schools should also provide students with an opportunity to contribute to the school by providing feedback from home teachers. Students are also involved in the learning contract decision-making process, where students are actively involved in formulating the guidelines (Ushiogi, 1988).

There is a focus on effective strategies and evidence-based teaching to increase student engagement. Teachers should also actively engage students to think about causalities in many 
cases (Tetsushima, 1993). The teachers should show an example of action to teach resilience to the students by enhancing motivation during lectures. In admitting errors, the students are taught to be courageous (Kikuchi, 2009).

Rewards should be provided for building and cultivating the confidence of students to express and share their views. With regard to the efforts to include the best learning atmosphere and opportunities to develop new skills that could maximize the outcome and accomplishment of learning, the school also should teach students how to solve real-life problems through procedures for problem-solving (Arai, 2004).

\section{Conclusion}

Many definitions have been offered for the term wellbeing, but the one which has been offered by Noble and McGrath defined Student wellbeing as a sustainable state of positive mood and attitude, resilience, and satisfaction with self, relationships and experiences at school (Noble $\&$ McGrath, 2012). The purpose of the present project was to review the research studies which have been carried on the topic of educational demotivation among Japanese students in general. This project reviews the possible causes of educational demotivation among Japanese students which could lead to their underachievement at times and seeks to contribute to the body of wellbeing research studies which have been conducted on various levels of education in Japan. In this review article, a total of 94 publications were yielded by the initial search criteria. After a review of abstracts, titles, and references, 10 potentially relevant articles were identified. Based on full-text, seven articles met the full inclusion criteria. Related titles and abstracts were reviewed to evaluate the educational demotivation through PROSPER model.

According to the findings of this review article, the increasing focus on student wellbeing is aimed at enhancing students' social, emotional and academic competence and diminishing youth depression, suicide, self-harm, antisocial behavior (including bullying and violence) and substance abuse. In keeping with the principles of positive psychology, which is the science of the conditions and processes leading to the maximum thriving of people, groups and organizations, the PROSPER framework was developed as an investigative device for the application of positive education (Noble \& McGrath, 2015). Due to its crucial function, the concept of motivation has been extensively investigated over the past thirty years in the field of second language learning (e.g., In spite of many research studies, a significant dimension of motivation, namely demotivation has not attracted the required attention from the scholars. On the significance of academic motivation, a barrage of studies claimed that there is a significant relationship between students' motivation and their academic functioning. Based on the rich literature, the fairest method to assess academic success, grades and the GPAs have been found to be by means of the most frequently utilized scales of academic output. The qualitative analysis revealed the causes of demotivation among the students, namely individual teacher's behavior in the classroom. In general, through programs that contribute to the optimization of the potential students, schools have adopted optimistic principles. Mental health development is part of a continuum that encompasses activities to prevent and care for the quality of an individual's mental state. School programs evaluated in compliance with the PROSPER model principles should at least be components of general prevention against the impeded future development of students while providing space for capability or potential building. However, as the purpose of 
the present project was to review the research studies that addressed educational demotivation among Japanese students, there are some gaps that need to be filled by further studies. These research investigations have all been fruitful for the educational context of Japan given the fact that they have all addressed the causes in-depth and offered many solutions for this serious crisis in the Japanese education system.

\section{References}

[1] Arai, K. (2004). What 'demotivates' language learners? A qualitative study on demotivational factors and learners' reactions. Bulletin of Toyo Gakuen University, 12, $39-47$.

[2] Asakawa, K. (2010). Flow experience, culture, and well-being: How do autotelic Japanese college students feel, behave, and think in their daily lives. Journal of Happiness Studies, 11(2), 205-223.

[3] Atkinson, J. (1974). Motivation and achievement. Winston and Sons.

[4] Bandura, A. (1986). Social foundations of thought and action: A social cognitive theory. Englewood Cliffs, NJ: Prentice-Hall.

[5] Bas, A. U., \& Firat, N. S. (2017). The views and opinions of school principals and teachers on positive education. Journal of Education and Training Studies, 5(2), 85-92.

[6] Beck, R. C. (2004). Motivation: Theories and principles. Pearson.

[7] Berger, C., Alcalay L., Torretti A., \& Milicic, N. (2011). Socio-emotional well-being and academic achievement: Evidence from a multilevel approach. Psicol. Reflex. Crít. 24 344-351.

[8] Brophy, J. (1983). Conceptualizing student motivation. Educational Psychologist, 18(3), 200-215.

[9] Brophy, J. (1998). Failure syndrome students. ERIC Clearinghouse on Elementary and Early Childhood Education, University of Illinois.

[10] Brown, H. (2000). Principles of language learning and teaching (4 ${ }^{\text {th }}$ ed.). Prentice-Hall.

[11] Busato, V. V., Prins, F. J., Elshout, J. J., \& Hamaker, C. (2000). Intellectual ability, learning style, personality, achievement motivation and academic success of psychology students in higher education. Personality and Individual Differences, 29(6), 1057-1068.

[12] Covington, M. V. (1992). Making the grade: A self-worth perspective on motivation and school reform. Cambridge University Press.

[13] Covington, M. V., \& Roberts, B. W., \& Weinstenin, C. E. (1994). Student motivation, cognition, and learning: Essays in Honor of Wilbert J. McKeachie. Lawrence Erlbaum.

[14] Deci, E. L., \& Ryan, R. M. (1985). Intrinsic motivation and self-determination in human behavior. Plenum Publishing Company. 
[15] Dulagil, A., \& Green, S., \& Ahern, M. (2016). Evidence-based coaching to enhance senior students' wellbeing and academic striving. International Journal of Wellbeing, 6(3), 131-149. doi:10.5502/ijw.v6i3.426

[16] Dörnyei, Z. (1994). Motivation and motivating in the foreign language classroom. Modern Language Journal, 78(3), 273-284.

[17] Dörnyei, Z. (1996). Moving language learning motivation to a larger platform for theory and practice. In R. L. Oxford (Ed.), Language learning motivation: Pathways to the new century (pp. 71-80). The University of Hawaii.

[18] Dörnyei, Z. (1998). Motivation in second and foreign language learning. Language Teaching, 31, 117-135.

[19] Dörnyei, Z. (2001). New themes and approaches in L2 motivation research. Annual Review of Applied Linguistics, 21, 43-59.

[20] Dörnyei, Z. (2002). The motivational basis of language learning tasks. In P. Robinson (Ed.), Individual differences and instructed language learning (pp. 137-158). Amsterdam: John Benjamins.

[21] Dörnyei, Z. (2003). Attitudes, orientations, and motivations in language learning: Advances in theory, research, and applications. In Z. Dörnyei (Ed.), Attitudes, orientations and motivations in language learning (pp. 3-32). Blackwell.

[22] Dörnyei, Z. (2005). The psychology of the language learner: Individual differences in second language acquisition. Lawrence Erlbaum.

[23] Dörnyei, Z. (2009). Motivation and the vision of knowing a second language. In B. Beaven (Ed.), IATEFL 2008: Exeter conference selections. Canterbury: IATEFL.

[24] Dörnyei, Z. (2010). The relationship between language aptitude and language learning motivation: Individual differences from a dynamic systems perspective. In E. Macaro (Ed.), Continuum companion to second language acquisition (pp. 247-267). Continuum.

[25] Dörnyei, Z., \& Ottó, I. (1998). Motivation in action: A process model of L2 motivation.Working Papers in Applied Linguistics (Thames Valley University, London), 4, 43-69.

[26] Dörnyei, Z., \& Ushioda, E. (2011). Teaching and researching motivation (2 ${ }^{\text {nd }}$ ed.). Longman.

[27] Dweck, C. S. (1986). Motivational processes affecting learning. American psychologist, 41(10), 1040.

[28] El Ansari W., Stock C. (2010). Is the health and wellbeing of university students associated with their academic performance? Cross sectional findings from the United 
Kingdom. International Journal of Environmental Research and Public Health, 7(2), 509-527. doi: 10.3390/ijerph7020509

[29] Falout, J., Elwood, J., \& Hood, M. (2009). Demotivation: Affective states and learning outcomes. System37(3), 403-417.

[30] Falout, J., \& Maruyama, M. (2004). A Comparative study of proficiency and learner demotivation. The Language Teacher, 28(8), 3-9.

[31] Galbraith, M. W. (1990). Education through community organizations. Jossey-Bass.

[32] Gardner, R. C. (1985). Social psychology and second language learning: The role of attitudes and motivation. Edward Arnold.

[33] Gutman, L. M., Vorhaus, J. (2012). The impact of pupil behaviour and wellbeing on educational outcomes. (Research report No. DFE-RR253). Childhood Wellbeing Research Centre. https://www.gov.uk/government/publications/the-impact-of-pupilbehaviour-and-wellbeing-on-educational-outcomes

[34] Green, S., Oades, L., \& Robinson, P. (2011). Positive education: Creating flourishing students, staff and schools. InPsych, 33(2), 16-18.

[35] Govindji, R., \& Linley, P. A. (2007). Strengths use, self-concordance and well-being: Implications for strengths coaching and coaching psychologists. International Coaching Psychology Review, 2, 143-153.

[36] Forsyth, D. R., \& McMillan, J. H. (1991). Practical proposals for motivating students. New directions for teaching and learning, 1991(45), 53-65.

[37] Hasegawa, A. (2004). Student demotivation in the foreign language classroom. Takushoku Language Studies, 107, 119-136.

[38] Irie, T., \& Kengo, Y. (2019). Effects of mindfulness and living condition on the wellbeing of first-year university students in Japan. Frontiers in Psychology, 10, 2831.

[39] Jarvis, M. (2005). The psychology of effective learning and teaching. Nelson Thrones Ltd.

[40] Kikuchi, K. (2009). Listening to our learners' voices: What demotivates Japanese high school students? Language Teaching Research, 13(4), 453-471.

[41] Kobayashi, K. (1989). Korede iinoka daigaku sentaku: Gendai koukousei no daigaku shingaku douki to shinro shidou o kangaeru [Do students make the right decisions in choosing their universities? The reasons behind considerations of current high school students on further university education, and academic and career counselling]. Seishounen Mondai [Youth Issues], 36, 20-27.

[42] Liu, Q., Shono, M., \& Kitamura, T. (2009). Psychological well- being, depression, and anxiety in Japanese university students. Depression and Anxiety, 26(8), E99-E105.

[43] Maehr, M. L., \& Nicholls, J. G. (1980). Culture and achievement motivation: A second look. Studies in cross-cultural psychology, 2, 221-267. 
[44] Manalo, E., Koyasu, M., Hashimoto, K., \& Miyauchi, T. (2006). Factors that impact on the academic motivation of Japanese university students in Japan and in New Zealand. Psychologia, 49(2), 114-131.

[45] Masgoret, A. M., \& Gardner, R. C. (2003). Attitudes, motivations, and second language learning: A meta-analysis of studies conducted by Gardner and associates. Language Learning, 53(1), 123-163.

[46] MacIntyre, P., Clément, R., Dörnyei, Z. \& Noels, K. (1998). Conceptualizing willingness to communicate in a L2: A situational model of 12 confidence and affiliation. The Modern Language Journal. 82(4). 545-562. 10.1111/j.1540-4781. 1998.tb05543. x.

[47] Nakano, K. (1990). Type A behavior, hardiness, and psychological well-being in Japanese women. Psychological Reports, 67(2), 367-370.

[48] Noble, T., \& McGrath, H. (2012). Wellbeing and resilience in young people and the role of positive relationships. In S. Roffey (Ed.), Positive relationships (17-33). Springer.

[49] Noble, T., \& McGrath, H. (2015). PROSPER: A new framework for positive education. Psychology of Well-being, 5(1), 1-17.

[50] Noble, T., \& McGrath, H. (2016). The PROSPER School Pathways for Student Wellbeing. Springer.

[51] Noels, K. A., Clément, R., \& Pelletier, L. G. (1999). Perceptions of teachers' communicative style and students' intrinsic and extrinsic motivation. Modern Language Journal, 83(1), 23-34.

[52] Norrish, J., Williams, P., O'Connor, M., \& Robinson, J. (2013). An applied framework for positive education. International Journal of Wellbeing. 3(2), 147-161. doi:10.5502/ijw.v3i2.2

[53] Novello A. C., Degraw C., Kleinman D. V. (1992). Healthy children ready to learn: An essential collaboration between health and education. Public Health Reports. 107(1), 3-15. PMC1403595

[54] Oxford, R., \& Shearin, J. (1994). Language learning motivation: Expanding the theoretical framework. The modern language journal, 78(1), 12-28.

[55] Pintrich, P. R. (2003). A motivational science perspective on the role of student motivation in learning and teaching contexts. Journal of Educational Psychology, 95(4), 667-686.

[56] Ray, A., \& Margaret, W. (Eds.). (2003). PISA programme for international student assessment (PISA): PISA 2000 Technical Report. OECD iLibrary. https://doi.org/10.1787/9789264199521-en.

[57] Ryan, R. M., \& Deci, E. L. (2000). The darker and brighter sides of human existence: Basic psychological needs as a unifying concept. Psychological Inquiry, 11(4), 319338. 
[58] Rotgans, J. I., \& Schmidt, H. G. (2012). The intricate relationship between motivation and achievement: Examining the mediating role of self-regulated learning and achievement-related classroom behaviors. International Journal of Teaching and Learning in Higher Education, 24(2), 197-208.

[59] Sakai, H., \& Kikuchi, K. (2009). An analysis of demotivators in the EFL classroom. System, 37(1), 57-69.

[60] Schleicher, A. (2014). Education in Japan: Learning to change. Organisation for Economic Cooperation and Development. The OECD Observer, 22.

[61] Schunk, D. H. (2008). Metacognition, self-regulation, and self-regulated learning: Research recommendations. Educational Psychology Review, 20(4), 463-467.

[62] Seligman, M. E. (2011). Building resilience. Harvard business review, 89(4), 100-106.

[63] Shimoyama, H. (1992). A study on the subclassification of moratorium of university students: Relation to the identity development. Japanese Journal of Educational Psychology, 40(2), 121-129. https://doi.org/10.5926/jjep1953.40.2_121

[64] Sogunro, O. A. (2014). Motivating factors for adult learners in higher education. International Journal of Higher Education, 4(1), 22-37.

[65] Steinmayr, R., \& Spinath, B. (2009). The importance of motivation as a predictor of school achievement. Learning and Individual Differences, 19(1), 80-90.

[66] Terjesen, M., Jacofsky, M., Froh, J., \& Digiuseppe, R. (2004). Integrating positive psychology into schools: Implications for practice. Psychology in the Schools. 41(1). 163-172. 10.1002/pits. 10148

[67] Thorkildsen, T. A. (2002). Literacy as a lifestyle: Negotiating the curriculum to facilitate motivation. Reading and Writing Quarterly, 18(4):321-341. doi: 10.1080/07487630290061863

[68] Ushiogi, M. (1988). Kyouiku o ikani doukizukeru ka. [How do we motivate students to learn?]. Gekkan Koukou Kyouiku Zoukangou, 110-114.

[69] Vroom, V. H. (1964). Work and motivation. Wiley.

[70] Wlodkowski, R. J. (1985). How to plan motivational strategies for adult instruction. Performance and Instruction, 24(9), 1-6.

[71] Yamawaki, N., Nelson, J. A. P., \& Omori, M. (2011). Self-esteem and life satisfaction as mediators between parental bonding and psychological well-being in Japanese young adults. International Journal of Psychology and Counselling, 3(1), 1-8.

[72] Ye, S., \& Ho, K. K. (2019). Would you feel happier if you have more protection behaviour? A panel survey of university students in Japan. Behaviour \& Information Technology, 38(4), 422-434. 
[73] York, T. T., Gibson, C., \& Rankin, S. (2015). Defining and measuring academic success. Practical Assessment, Research, and Evaluation, 20(1), Article 5. 